\title{
Patient or Physician - Who Is Able to Evaluate Gastroesophageal Reflux Disease Symptoms Better?
}

\author{
Anita Gasiorowska \\ Department of Digestive Tract Diseases, Medical University of Lodz, Lodz, Poland
}

\author{
Article: Physicians and patients measure different dimension on assessment for gastroesophageal reflux dis- \\ ease-related symptoms \\ Lopez-Alvarenga JC, Sobrino-Cossio S, Fass R, Vargas-Romero JA \\ (J Neurogastroenterol Motil 2011;17:381-386)
}

Gastroesophageal reflux disease (GERD) is one of the most prevalent gastrointestinal (GI) disorders in Western countries. It is estimated that for an adult population, daily symptoms occur in approximately $5 \%$ to $10 \%$ of population and once a week symptoms in $8 \%$ to $29 \% .^{1-3}$ Moreover, the prevalence of GERD has increased tenfold in the years from 1970 to $1995 .^{4,5}$

Diagnostics modalities for GERD include the medical history, symptom questionnaires, upper GI endoscopy, 24 hour esophageal $\mathrm{pH}$-monitoring and the proton pump inhibitor (PPI) test. During the last decade it has been recognized that majority of patients with reflux disease do not have endoscopically visible mucosal lesions. ${ }^{6}$ In the past many physicians and scientists were skeptical about the symptom assessment after treatment and rather tended to analyze data from endoscopy, however, perspective the therapeutic effect of a drug on the symptoms is most important from patient's perspective. Upper endoscopy is an expensive and invasive examination, and therefore it is difficult to consider this method as useful in assessment of treatment effects of patients with GERD. It seems that the best methods to measure the therapeutic efficacy are symptom assessment and symptom improvement. Reliable and valid evaluation methods are most needed for clinical trials of GERD therapies. Although, according to many researchers, most recent assessment scales are insufficient for a full and reliable assessment of the different types of GERD.

For the quantitative evaluation of symptoms of the disease and the influence on quality of life, different types of questionnaires are used as assessment tools to evaluate the treatment effect. They are used in determining diagnosis of GERD, and also in evaluation of different types of treatment. A number of symptom scales and questionnaires have been used in clinical trials, but not all of them have been fully validated. Furthermore, these scales should be objective, relevant to clinical practice, practical for use and economical with low price. ${ }^{7}$ During designing symptom scales for GERD evaluation, it is important to remember about the whole spectrum of GERD symptoms, includ-

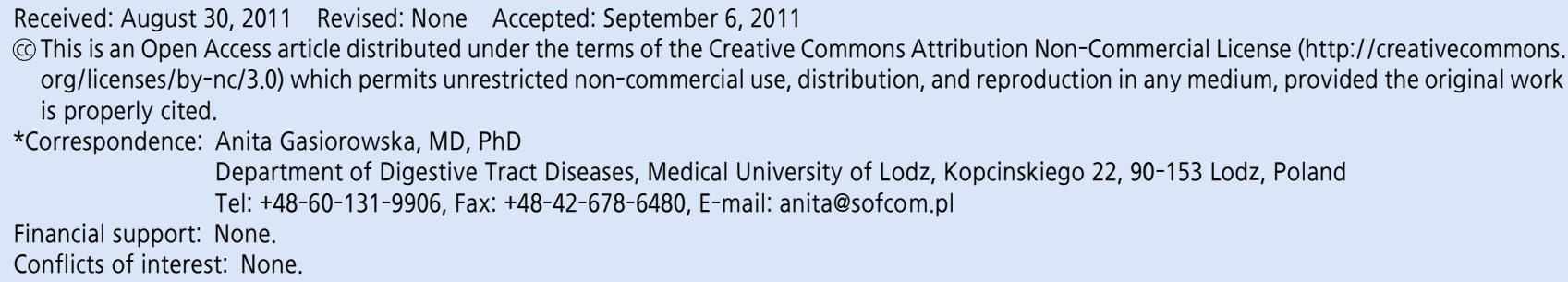


ing typical and atypical ones. The multidimensional symptom scale should cover all types of symptoms. Additionally, sometimes it is difficult to assess symptoms reliably at a single time point, because GERD symptoms may occur episodically and may be triggered by food, stress and physical exercise. Sometimes presence of typical and atypical symptoms of GERD, causes significant impact on daily activities and reduction of physical strength. Additionally, scales should be available in different languages for use in international studies and for multinational comparison.

During analysis of GERD symptoms, it is essential not to forget about possibility of discrepancies between documented gastroesophageal reflux, esophageal injury and the presence of symptoms. As it has been discovered, relationship between symptoms and the presence and severity of esophagitis is poor. ${ }^{8}$ Moreover in many patients with extraesophageal symptoms such as cough and hoarseness typical symptoms may be absent. ${ }^{9,10}$

In this issue of the Journal, Lopez-Alvarenga et $\mathrm{al}^{11}$ evaluated the existence of correlation between physician and patient measurement of symptoms in GERD. Authors started to use expression clinimetrics, which are measurement of clinical symptoms and procedure that help in diagnosis, characterization or evaluation of clinical entities. Besides, they pointed out that, in order to characterize treatment efficacy, the clinical endpoints have to be properly evaluated. That is why, patients were using reflux questionnaire - ReQuest, symptom assessment tool developed for the use in GERD patients which validity, reliability and high responsiveness have been documented in patients with GERD. ${ }^{12}$ Whereas, physicians used a questionnaire which consisted of 18 questions on classical symptoms of GERD, dyspepsia and extraesophageal manifestations. In the past the authors demonstrated that this structured interview had enough sensitivity to detect group differences in symptom severity or its changes by PPI treatment. $^{13,14}$

The authors revealed that symptoms severity of GERD assessed by physicians did not correlate with symptoms severity assessed by patients. However, both tools recorded improvement of patient's symptoms after 4 weeks of treatment by pantoprazole. In previous reports, there were many suggestions regarding who should assess the symptoms in GERD patients such as - investigator, nurse, psychologist or patients. Some authors believed that the patients might not be able to recognize or identify symptoms using the same terminology as nurses or physicians. Thus, self-assessment scales need to be easily understood by patients aided with "word pictures" to describe symptoms rather than medical terms. ${ }^{15}$ Self-assessment of symptoms is the best choice because it is the patients neither the investigator nor the nurse who experiences the symptoms. This form of symptom assessment is usually associated with lower cost, and considering the high prevalence of GERD, it may have significant economic impact. Moreover some authors highlighted that physicians tended to underscore the severity of symptoms. ${ }^{16}$ Current research studies indicated that even when physicians and patients were evaluating the same disease, the dimensions measured were not the same. The principal symptoms of GERD are heartburn and regurgitation which have been discovered many years ago and heartburn, when it is the predominant symptom, may be the basis for the diagnosis of reflux disease. Many patients with GERD report multiple symptoms referable to the GI tract, including those that may be attributable to functional dyspepsia and irritable bowel syndrome, therefore assessment method is very complex. ${ }^{17}$ For example, a recent study reported that a significant proportion of patients with GERD symptoms also experienced symptoms compatible with the diagnosis of the irritable bowel syndrome and functional dyspepsia. ${ }^{18}$ Additionally, co-morbid psychological distress was reported more commonly in patients with GERD symptoms. Population-based studies have identified psychiatric disease as a risk factor for GERD symptoms. ${ }^{19,20}$ Recently Nojkov et $\mathrm{al}^{21}$ showed that co-morbid psychological distress was independently associated with more severe GERD symptoms at baseline and more residual symptoms after PPI therapy. These data suggest that co-morbid IBS or psychological distress may influence the assessment of GERD symptoms by patients.

Rigorous development of interview methods or questionnaires requires identifying accurate descriptive wording for symptoms. Traditionally, experts define symptoms with limited input from patients regarding the content and clarity of definitions. Generally, heartburn is a term which is poorly identified by patients and often misinterpreted. That is why patient responses are not consistent with the definition of heartburn used by physician. $^{22}$

Additionally in this study, authors found out that the medical specialty of the physician influenced the perception of the symptom severity of GERD. It happens probably, because patients with different predominant symptoms are treated by doctors of different specialties. Most of the patients seen by primary care physicians for GERD have wide spectrum of symptoms from classical heartburn symptoms through abdominal pain to respiratory symptoms. On the other hand, patients consulted from the 
primary care physicians, usually go to the surgeon if symptoms persist.

Symptoms are an important part of GERD treatment outcome and may be included as part of a disease specific instrument. Work of Lopez-Alvarenga and colleagues ${ }^{11}$ suggests that questionnaires filled by patients and physician driven tools do not correlate because they measure diverse orthogonal dimensions and structured approach to assess treatment response may be the preferred diagnostic method. However, the question asked by researchers during the discussion: who should perform the measurement - physician or patient - still remains without a definite answer.

\section{References}

1. Dent J, El-Serag HB, Wallander MA, Johansson S. Epidemiology of gastroesophageal reflux disease: a systematic review. Gut 2005; 54:710-717.

2. Diaz-Rubio M, Moreno-Elola-Olaso C, Rey E, Locke GR 3rd, Rodriguez-Artalejo F. Symptoms of gastroesophageal reflux: prevalence, severity, duration and associated factors in a Spanish population. Aliment Pharmacol Ther 2004;19:95-105.

3. Ruigómez A, García Rodríguez LA, Wallander MA, Johansson S, Graffner H, Dent J. Natural history of gastroesophageal reflux disease diagnosed in UK general practice. Aliment Pharmacol Ther 2004:20:751-760.

4. Fullard M, Kang JY, Neild P, Poullis A, Maxwell JD. Systemic review: does gastro-oesophageal reflux disease progress? Aliment Pharmacol Ther 2006;24:33-45.

5. Castell DO, Murray JA, Tutuian R, Orlando RC, Arnold R. Review article: the pathophysiology of gastro-oesophageal reflux disease - oesophageal manifestations. Aliment Pharmacol Ther 2004;20(suppl 9):14-25

6. Sharma P, Chey W, Hunt R, Laine L, Malfertheiner P, Wani S. Endoscopy of the esophagus in gastroesophageal reflux disease: are we losing sight of symptoms? Another perspective. Dis Esophagus 2009;22:461-466.

7. Stanghellini V, Armstrong D, Mönnikes H, Bardhan KD. Systematic review: do we need a new gastroesophageal reflux disease questionnaire? Digestion 2007;75(suppl 1):3-16.

8. Locke GR, Zinsmeister AR, Talley NJ. Can symptoms predict endoscopic findings in GERD? Gastrointest Endosc 2003;58:661-670.

9. Moore JM, Vaezi MF. Extraesophageal manifestations of gastroesophageal reflux disease: real or imagined? Curr Opin Gastroenterol
2010;26:389-394.

10. Malagelada JR. Review article: supra-esophageal manifestations of gastro-oesophageal reflux disease. Aliment Pharmacol Ther 2004; 19(suppl 1):43-48.

11. Lopez-Alvarenga JC, Sobrino-Cossio S, Fass R, Vargas-Romero JA. Physicians and patients measure different dimension on assessment for gastroesophageal reflux disease-related symptoms. J Neurogastroenterol Motil 2011;17:381-386.

12. Armstrong D, Mönnikies H, Bardhan KD, Stanghellini V. The construction of a new evaluative GERD questionnaire - methods and state of the art. Digestion 2004;70:71-78.

13. Lopez-Colombo A, Lopez-Alvarenga J, Vargas J, et al. Do prior pregnancies modify the intensity of symptoms related to GERD? A report of the Mexican GERD working group. Gut 2008;57:A312.

14. Lopez L, Lopez-Alvarenga JC, Comuzzie AG, Gonzalez J, Crespo Y, Vargas J. Nighttime GERD symptoms associated with dyspepsia, esophageal discomfort, and extraesophageal complaints improvement after treatment with pantoprazole magnesium $40 \mathrm{mg}$ daily for 28 days. Gastroenterology 2008;134(suppl 1):A176-A177.

15. Bardhan KD, Stanghellini V, Armstrong D, Berghöfer P, Gatz G, Mönnikes H. Evaluation of GERD symptoms during therapy. Part I. Development of the new GERD questionnaire ReQuest. Digestion 2004;69:229-237.

16. McColl E, Junghard O, Wiklund I, Revicki DA. Assessing symptoms in gastroesophgeal reflux disease: how well do clinicians' assessment agree with theose of their patients? Am J Gastroenterol 2005; 100:11-18.

17. Talley N, Dennis E, Schettler-Duncan VA, Lacy BE, Olden KW, Crowell MD. Overlapping upper and lower gastrointestinal symptoms in irritable bowel syndrome patients with constipation or diarrhea. Am J Gastroenterol 2003;98:2454-2459.

18. Locke GR 3rd, Zinsmeister AR, Fett SL, Melton LJ 3rd, Talley NJ. Overlap of gastrointestinal symptom complexes in a US community. Neurogastroenterol Motil 2005;17:29-34.

19. Avidan B, Sonnenberg A, Giblovich H, Sontag SJ. Reflux symptoms are associated with psychiatric disease. Aliment Pharmacol Ther 2001;15:1907-1912.

20. Stanghellini V. Relationship between upper gastrointestinal symptoms and lifestyle, psychosocial factors and comorbidity in the general population: results from the Domestic/International Gastroenterology Surveillance Study (DIGEST). Scand J Gastroenterol 1999; 231(suppl):29-37.

21. Nojkov B, Rubenstein JH, Adlis SA, et al. The influence of co-morbid IBS and psychological distress on outcomes and quality of life following PPI therapy in patients with gastro-oesophageal reflux disease. Aliment Pharmacol Ther 2008;27:473-482.

22. Shaw M. Diagnostic utility of reflux disease symptoms. Gut 2004; 53(suppl 4):iv25-iv27. 